\title{
Growth of ZIF-8 Membranes on Ceramic Hollow Fibers by Conversion of Zinc Oxide Particles
}

Yang Wang ${ }^{\dagger}$, Hangliao Zhang ${ }^{\dagger}$, Xiaobin Wang*, ${ }^{*}$, Chengxian Zou ${ }^{\dagger}$, Bo Meng ${ }^{\dagger}$, and Xiaoyao $\operatorname{Tan}^{\sharp}$

†School of Chemistry and Chemical Engineering, Shandong University of Technology, Zibo 255000, China.

†Department of Chemical Engineering, Tianjin Polytechnic University, Tianjin 300387, China. Corresponding Author. wangxiaobin@sdut.edu.cn (X. Wang).

\section{Characterizations}

The surface morphologies and cross-section views of hollow fibers and ZIF-8 membranes were examined by field emission scanning electron microscopy (FESEM, FEI Sirion 200, Netherlands). The distribution of elements was identified using an energy dispersive X-ray (EDX) equipped on the SEM. Crystal phase of samples were conducted on a Brucker D8 Advance X-ray diffractometer with $\mathrm{Cu}-\mathrm{K} \alpha$ radiation $(\lambda=0.1542 \mathrm{~nm})$ at $35 \mathrm{kV}$ and $30 \mathrm{~mA}$. Single gas permeation tests were performed in a home-made permeation cell using $\mathrm{H}_{2}, \mathrm{~N}_{2}, \mathrm{CO}_{2}$ and $\mathrm{CH}_{4}$ gases. The separation performance of binary gas mixtures was analyzed by the online gas chromatographs (GC-6890N). The membranes were sealed into a home-made stainless steel using rubber O-rings. The feed stream was pressurized and the downstream pressure was maintained at atmospheric pressure. The gas permeation was measured by a ADM flow meter (Agilent). The mechanical strength of $\mathrm{Al}_{2} \mathrm{O}_{3}-\mathrm{ZnO}$ hollow fibers was calculated by three-point bending test according to previous reports. ${ }^{1-3}$ The bending strength can be expressed by the following equation: 


$$
\sigma_{F}=\frac{8 F L D}{\pi\left(D^{4}-d^{4}\right)}
$$

where $\sigma_{\mathrm{F}}$ is bending strength, $\mathrm{F}$ is the recorded force at which fracture takes place; $\mathrm{L}$ is the length;

$\mathrm{D}$ and $\mathrm{d}$ are the outer and inner diameter.

\section{The EDX analysis of $\mathrm{Al}_{2} \mathrm{O}_{3}-\mathrm{ZnO}$ hollow fiber}

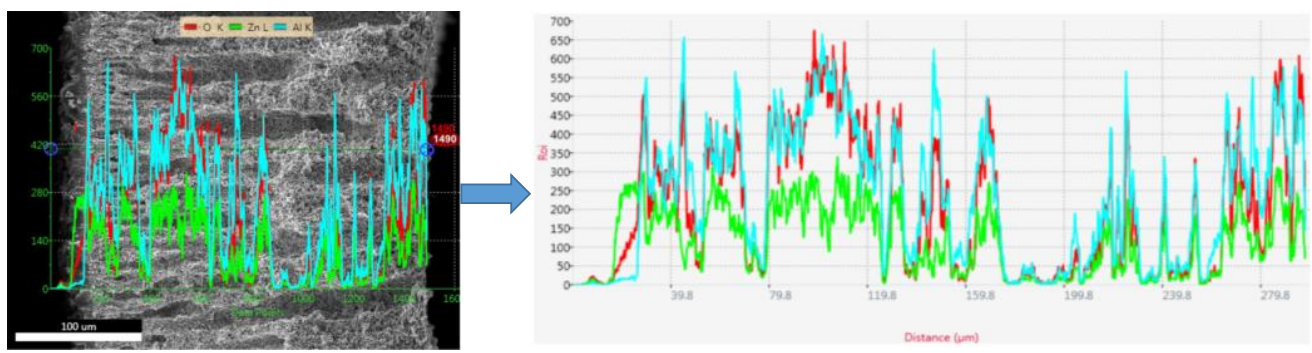

Figure S1. EDX cross-section line scans of ZIF-8 membrane supported on the $\mathrm{Al}_{2} \mathrm{O}_{3}$ hollow fibers containing $25 \mathrm{wt} . \% \mathrm{ZnO}$ particles.

3. SEM images of $\mathrm{ZIF-8}$ membranes supported on $\mathrm{Al}_{2} \mathrm{O}_{3}-\mathrm{ZnO}$ hollow fibers without activation.
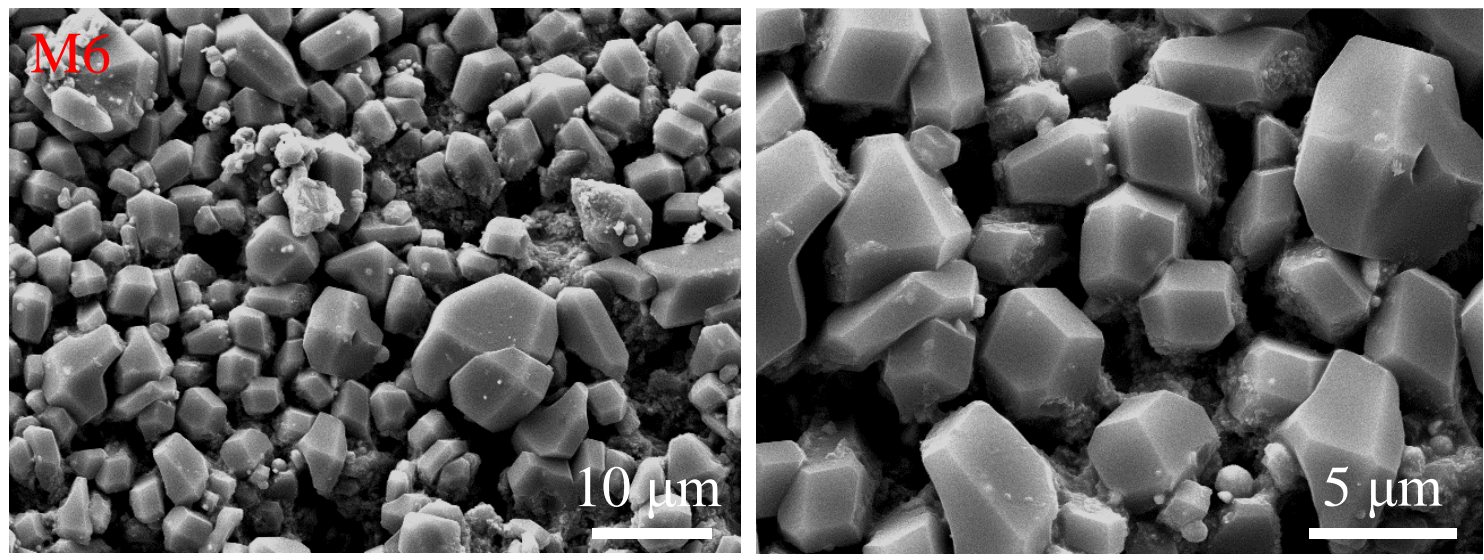

Figure S2. SEM images of ZIF-8 membranes supported on $\mathrm{Al}_{2} \mathrm{O}_{3}-\mathrm{ZnO}$ hollow fibers (M6$25 \mathrm{wt} . \% \mathrm{ZnO}$ ) without activation.

4. The growth behavior as a function of activation temperature and concentration for ZIF8 membranes 


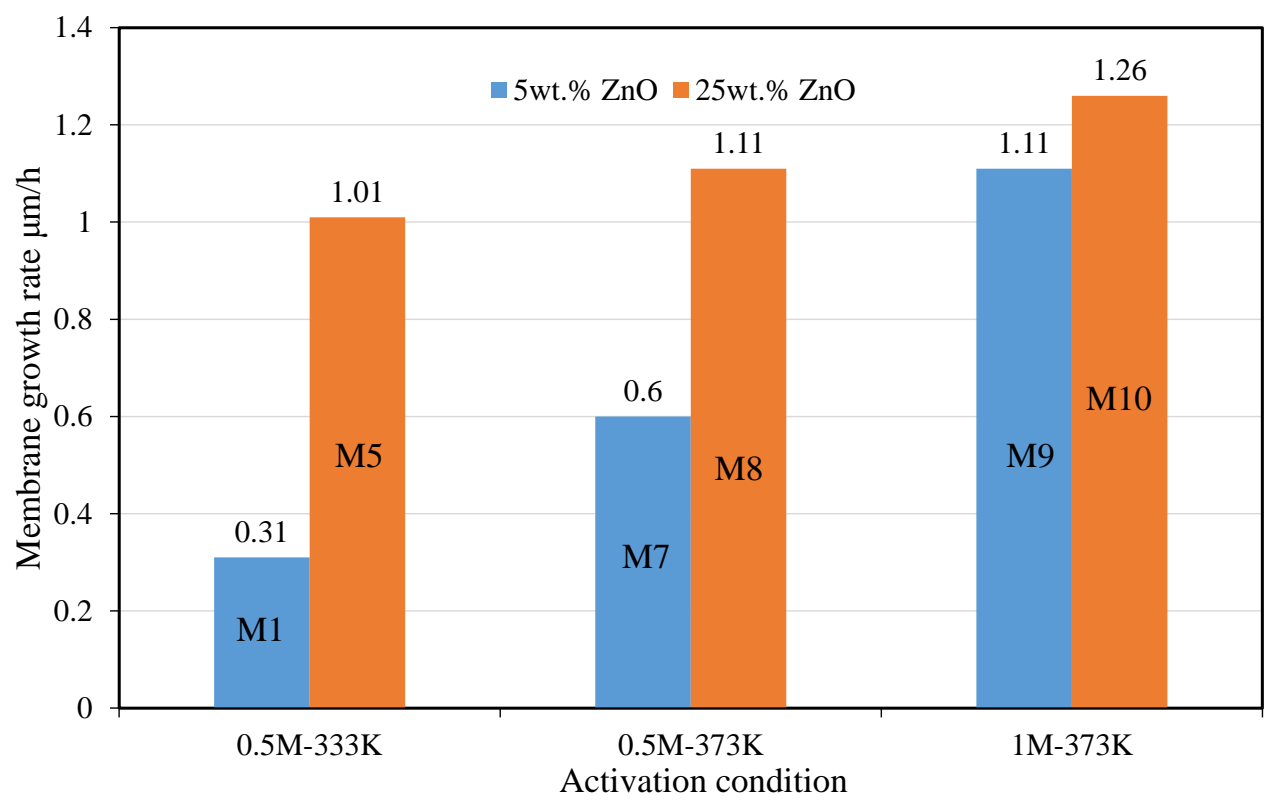

Figure S3. The growth behavior as a function of activation temperature and concentration for ZIF-8 membranes (M1, M5, M7-M10) supported on $\alpha-\mathrm{Al}_{2} \mathrm{O}_{3}$ hollow fibers containing $5 \mathrm{wt} . \%$ and $25 \mathrm{wt} . \% \mathrm{ZnO}$, respectively.

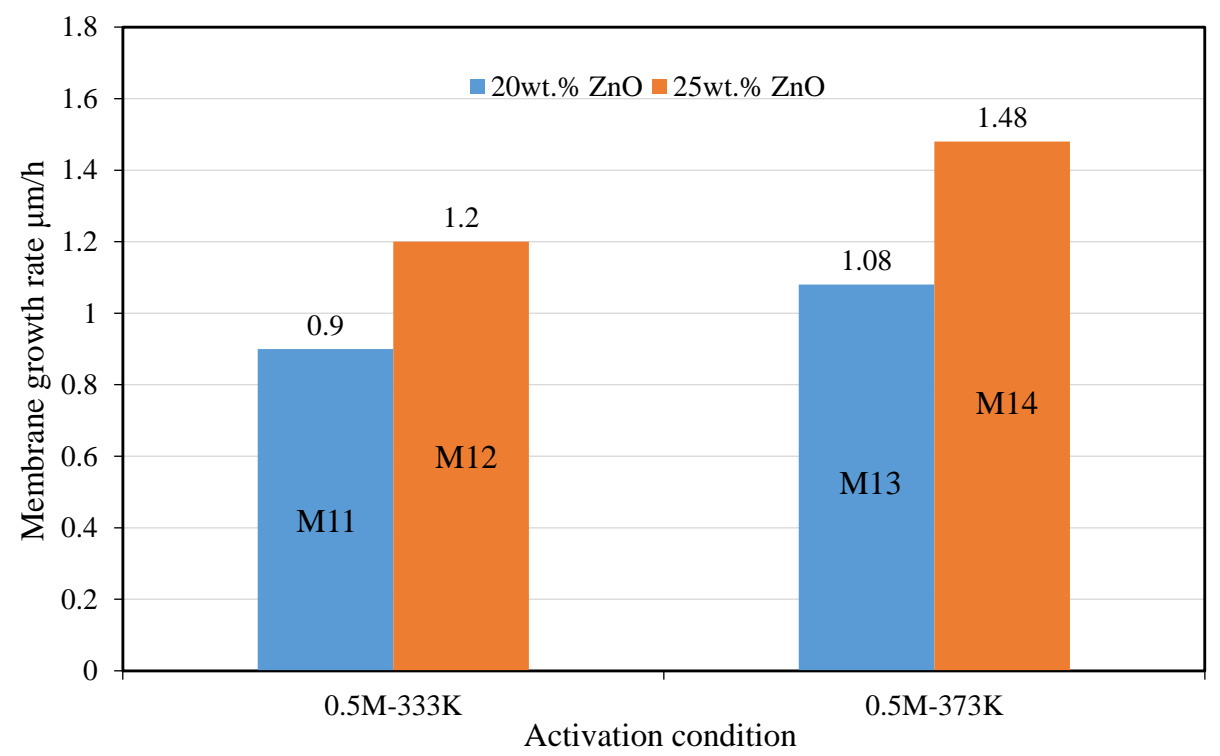

Figure S4. The growth behavior as a function of activation temperature and concentration for ZIF-8 membranes (M11-M114) supported on $\alpha-\mathrm{Al}_{2} \mathrm{O}_{3}$ hollow fibers containing $20 \mathrm{wt} . \%$ and $25 \mathrm{wt} . \% \mathrm{ZnO}$, respectively.

\section{REFERENCES}


(1) Liu, S.; Li, K; Hughes, R. Preparation of porous aluminum oxide $\left(\mathrm{Al}_{2} \mathrm{O}_{3}\right)$ hollow fiber membranes by a combined phase-inversion and sintering method. Ceram. Int. 2003, 29, 875-881.

(2) Maneerung, T.; Hidajat, K.; Kawi, S. Ultra-thin $(<1 \mu \mathrm{m})$ internally-coated Pd-Ag alloy hollow fiber membrane with superior thermal stability and durability for high temperature $\mathrm{H}_{2}$ separation. J. Membr. Sci. 2014, 452, 127-142.

(3) Gil, A.G.; Reis, M.H.M.; Chadwick, D.; Wu, Z.; Li, K. A highly permeable hollow fibre substrate for $\mathrm{Pd} / \mathrm{Al}_{2} \mathrm{O}_{3}$ composite membranes in hydrogen permeation. Int. J. Hydrogen Energy 2015, 40, 3249-3258. 